\title{
Influence of Vibration on Free Convection Heat transfer from Sinusoidal Surface
}

\author{
Zena K. Kadhim \\ Professor of Wasit University \\ Iraq, Wasit Province, University of Wasit
}

\author{
Hadi O. Mery \\ University of Wasit \\ Iraq, Wasit Province, University of Wasit
}

\begin{abstract}
The influence of forced vibration on the free convection heat transfer from a sinusoidal surface has been experimentally investigated in this paper. A copper plate of $[350 \times 150 \times 10$ $\mathrm{mm}$ ] length, width and thickness respectively has been used as a test sample where, the upper surface of this plate is manufactured by a wire-cutting machine as a sinusoidal surface with 0.3 amplitude to wavelength ratio. This plate is heated by electric heater under constant heat flux conditions ranging as $\left[250,500,750,1000,1250\right.$ and $\left.1500 \mathrm{~W} / \mathrm{m}^{2}\right]$ and subjected to vertical forced vibration with frequencies $[5,10$, 15,20 and $25 \mathrm{~Hz}$ ] and [3, 4 and $5 \mathrm{~mm}$ ] peak to peak vibration amplitude, the Rayleigh number $(\mathrm{Ra})$ ranging from $\left[1.5 \times 10^{8}\right.$ to $4.0 \times 10^{8}$ ], the vibrational Reynolds number $\left(R e_{v}\right)$ ranging as $\left[2 \times 10^{3}, 4 \times 10^{3}, 6 \times 10^{3}, 8 \times 10^{3}\right.$ and $\left.10 \times 10^{3}\right]$ and the Prandtl number ranging from $[0.707$ to 0.710$]$ at the ambient laboratory conditions approximately $\left(25^{\circ} \mathrm{C}\right)$ and pressure of $(1$ bar). This study is performed for three different positions of sinusoidal surface: horizontal, vertical and facing downward positions. This study concluded that the influence of vibration generally enhances the heat transfer rate and the vibrational mean Nesselt number $\left(N u v_{\text {mean }}\right)$; however the amount of this enhancement depending on the vibrational Reynolds number, Rayleigh number and the position of the heated surface as shown in the following empirical equations:
\end{abstract}

For the horizontal position

$N u v_{\text {mean }}=41.547 * R a^{0.091} * R e_{v}^{0.017}$

For the vertical position

$N u v_{\text {mean }}=22.66 * R a^{0.119} * R e_{v}{ }^{0.018}$

For the facing downward position

$N u v_{\text {mean }}=0.98 * R a^{0.269} * R e_{v}{ }^{0.037}$

\section{General Terms}

$N u_{\text {mean }}$ : the mean Nusselt number, $R e_{\mathrm{v}}$ : vibrational Reynolds number, Nuv mean: vibrational mean Nesselt number, $R a$ : Rayleigh number, $q^{\approx}$ : heat flux $\left(W / m^{2}\right), Q_{g e n}$ : Heat generation as a result of the passage of an electric current $(W a t t), V$ : the voltage (Volt), I: the current $(A m p), Q_{\text {conv }}$ : thermal energy transmitted by convection (Watt), $Q_{\text {rad }}$ : thermal energy transmitted by radiation (Watt), $Q_{\text {cond }}$ : Thermal energy transmitted by conduction (Watt), $L_{c}: \quad$ Characteristic length $(m)$, $f$ : Vibration frequency $(\mathrm{Hz}), a_{v}$ : vibrational amplitude $(m)$, $v$ : Kinematic viscosity of air $\left(\mathrm{m} / \mathrm{s}^{2}\right)$, $\beta$ : Thermal expansion coefficient $(1 / K), g$ : acceleration of the gravity $=9.81\left(\mathrm{~m} / \mathrm{s}^{2}\right), L$ : the length of test sample $(\mathrm{m})$, $T_{\infty}$ : The fluid temperature $\left({ }^{\circ} \mathrm{C}\right), T_{\text {sav }}$ : average surface temperature $\left({ }^{\circ} \mathrm{C}\right)$, Nuvx: vibrational local Nesselt number, Pr: Prantl number, hvx: vibrational local heat transfer coefficient $\left(\mathrm{W} / \mathrm{m}^{2} \cdot{ }^{\circ} \mathrm{C}\right), K$ : thermal conductivity of fluid $\left(W / m .{ }^{\circ} \mathrm{C}\right), x$ and $y$ : Cartesian coordinates.

\section{Keywords}

Free convection, influence of vibration on heat transfer, heated facing downward, vibrational Nesselt number.

\section{INTRODUCTION}

The fast technological progress of nowadays has directed the attention of research workers to investigate possible techniques of heat transfer augmentation in various engineering systems. Some of such techniques resort to modifying of heat transfer surfaces, introducing vortex generators at inlet, applies an electrostatic field, modifying the duct cross section, and vibrating the heat transfer surface. These techniques generally result in an increased heat transfer coefficient due to the change in the flow pattern; however, during recent years, considerable attention has been focused on heat transfer augmentation by means of vibration and modifying of heat transfer surface.

One of the practical problems, which originally inspired interest in the effect of vibration on heat transfer, was encountered in rocket propulsion motors. As combustion instability of high amplitude occurred in such motors, the local heat transfer to the motor walls drastically increased and the wall temperature rose to the point where the motor was destroyed [1].

The influence of vibration on the convective heat transfer which has been investigated in the past studies for cylinders, flat plate and other geometries and has carried out for different directions of applied vibration relative to these surfaces and for various ranges of applied frequency and amplitude and for different thermal boundary conditions. The results of these investigations show that the vibration gives a large increase to none increase or even decrease in the heat transfer rate [2].

The past studies in this field dealt with the effect of vibrations on the heated surfaces by two ways. In the first way, the surface is held stationary and acoustic vibrations are imposed in the fluid medium which is surrounding the surface; whereas the other way, a vibrational motion is applied on the heated surface itself [3].

On the other hand, the study of free convection heat transfer from the surfaces with complex geometry has received considerable attention due to its practical applications. The corrugated surfaces are encountered in many applications such as electronic cooling, flat plate solar collectors and flat plate evaporators in refrigerators. The sinusoidal wavy surface encompasses all other roughened surfaces and can be viewed as an approximation to many practical geometries for which free convection heat transfer is topic of interest [4]. 
Corrugation surface is very important for heat transfer analysis as it has a significant thermal characteristic. There are different types of corrugations like trapezoidal, sinusoidal, Vee, and rectangular wave. Each one has different significant heat transfer enhancement ability; therefore the convection in the presence of the corrugation has a great importance in the thermal engineering [5].

Bhavnan et al. 1991 presented an experimental study of the natural convection heat transfer from the sinusoidal wavy surface on vertical plates which showed that the heat transfer is increased (maximum increase) by about $(15 \%)$ at an amplitude to wavelength ratio of (0.3) compared with the flat plate[6]; however the influence of harmonic oscillations on free convective heat transfers is investigated by $\mathbf{K}$. KRISHNA PRASAD [2], 1971 who showed that the maximum increase in heat transfer rate of vertical plate is (33\%) for comparison with non-vibrational case. The influence of vibration on heat transfer is conducted for many test geometries but the corrugated plate is appeared in the study of M. A. Saleh [1], 2006, for V-shaped grooves and square-shaped grooves where this experiment shows that vibration is a powerful enhancement tool, the heat rate increasing more than 2.5 fold; while Abdalhamid R. Sarhan [7], 2013, conducted the investigation of the influence of vibration on the free convection from the longitudinally finned plate and he reported a good enhancement of heat transfer rate due to vibration's applying.

\section{OBJECTIVES OF THE RESEARCH}

\subsection{The Aims}

The proposed study aims to achieve experimental investigation of the influence of vibration on the heat transfer from the sinusoidal surface heating upward and downward in different positions with constant heat flux.

\subsection{The Scope}

Design and manufacture a copper plate has a sinusoidal upper surface with optimum amplitude to wavelength ratio.

Make an experimental study of the effect of applying a forced vibration on the heat transfer from a copper plate is heated upward and downward in different positions with constant heat flux.

Estimate the empirical equations to govern the experimental results of this study. Make a comparison of the results of the mean Nesselt number in both cases, with vibration and without vibration at the same boundary conditions in each position.

Make a comparison of the results of this study with the previous studies.

\section{THEORITICAL EQUATIONS}

The total heat that is generated by the heater can be calculated as [8]:

$Q_{\text {gen }}=V * I$

So that the amount of heat transferred by convection from the corrugated surface can be calculated from the equation follows:

$$
Q_{\text {conv }}=Q_{\text {gen }}-Q_{\text {rad }}-Q_{\text {cond }}
$$

The vibrational Reynolds number is the ratio between the inertia force to the viscous force of the boundary layer of velocity, which results from the vibrations [7].
$R e_{v}=\frac{2 \pi * f * a_{v} * L_{c}}{v}$

The Rayleigh number is defined as the ratio between the buoyancy force and the viscous force [9].

$R a=\frac{\beta * g *\left(T_{s a v}-T_{\infty}\right) * L_{c}^{3}}{v^{2}} * \operatorname{Pr}$

The vibrational local Nesselt number can be calculated as:

$N u v x=\frac{h v x * L_{c}}{K}$

So that the vibrational mean Nesselt number is found as [10]:

$N u v_{\text {mean }}=\frac{1}{L} \int_{0}^{L} N u v x d s$

\section{EXPERIMENTAL APPARATUS}

In order to achieve the aim of this study, design and fabricate the apparatus which consists of the test sample and the vibration rig.

\subsection{Test Section}

The test section includes the heater, insulations, thermocouples and the test sample which is a copper plate with $(32 \times 15 \times 1 \mathrm{~cm})$ dimensions; the upper surface is manufactured as a corrugated surface by wire-cutting machine while the base of plate remains flat with a thickness of (2 $\mathrm{mm}$ ). The corrugated surface has specifications of a sine-wave form with a function profile is:

$\mathrm{y}=3 * \sin 6 ! \llbracket(2 \pi \mathrm{x} / 10) \rrbracket$

As well as it has optimum and effective amplitude to wavelength ratio is $(0.3)$.

Fig 1: shows the photograph of manufacturing of the sinusoidal surface by wire cutting machine with corrugation amplitude $(3 \mathrm{~mm})$, wavelength is $(10 \mathrm{~mm})$ and number of waves is (35).

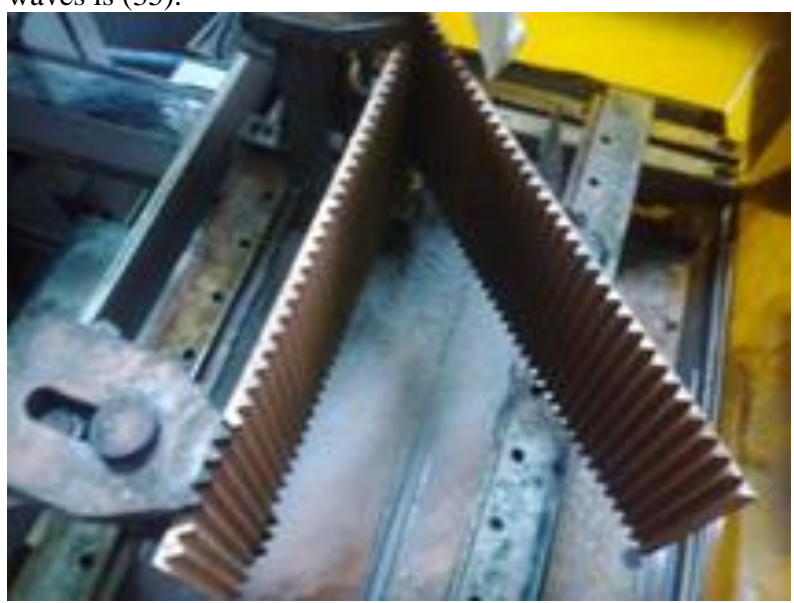

Fig 1: Photography of manufacturing by wire-cutting machine.

\subsection{Vibration System and Vibration Rig}

The vibration system is very important and sensitive system because it has accurate devices and other requirements to generate, calibrate and measure the vibration parameters. The devices that are used in this system are the function generator, oscilloscope, power amplifier, shaker and vibration meter. In order to make these devices match the test section and fit with work requirements and conditions, the vibration rig is manufactured to meet these requirements and to overcome some work challenges. 
The vibration rig is built and designed from a cubic block of wood with dimensions $[30 \times 30 \times 70 \mathrm{~cm}]$ length, width and height respectively, and it has a relatively wide square base to fix the rig on the ground, and there are two grooved wooden pillars constructed on the two sides of the block with total height $110 \mathrm{~cm}$. Vibration exciter is installed on the wood block and tightened by four screws through a thin wooden washer to absorb the backlash vibrations of the base of the device. The vibrating part of the exciter device is connected to $\mathrm{U}$ shape holder by a bolt from the concave and the $\mathrm{U}$ shape in turn holds the test section by two bolts in its open ends so as to permit to the test section to rotate 360 degrees to enable different positions study for the test section.

A one-way sliding channel is placed inside the grooves of the side wooden pillars and it is tied to the $\mathrm{U}$ shape holder to restrict the side movement of the test section and to allow the up-down movement only to ensure applying a vertical vibration on the plate without any side vibrations.

As well known, the exciter is very sensitive and expensive device and it doesn't bear long-time operation under high weight load; therefore two springs are used to hang the test section to reduce the load and the pressure on the device and to raise its efficiency.

Fig 2 illustrates the vibration rig where A) represents a real photography; while B) represents a schematic of the vibration rig where the legend as follows:

1: two spring to reduce the load; 2: test samples; 3 : the Ushape holder; 4: the exciter; 5 : one-way sliding channels; 6 : the wooden frame (block, two pillars and the base).

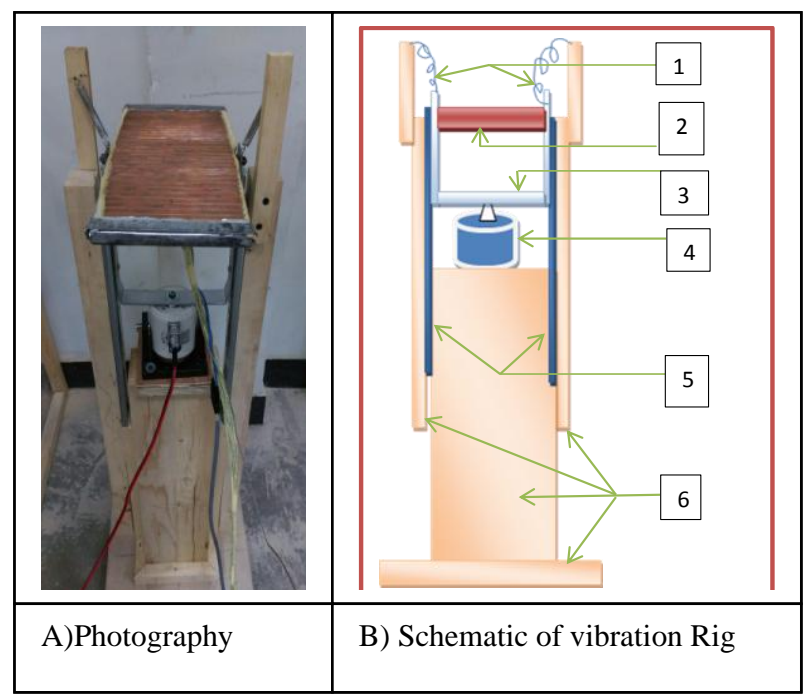

Fig 2: The Vibration Rig.

\subsection{Measurement Devices}

Various types of measurement devices are used in this study because of the variety of measured parameters where Oscilloscope and the vibration meters are used to the vibration monitoring, while the electric variables is measured by AVO meter and Clamp meter; however the thermocouples and thermal Camera to deal with the temperature measurement; where Fig 3 shows the photography of thermal camera; whereas the Fig 4 illustrates a photography of installation of the whole system.

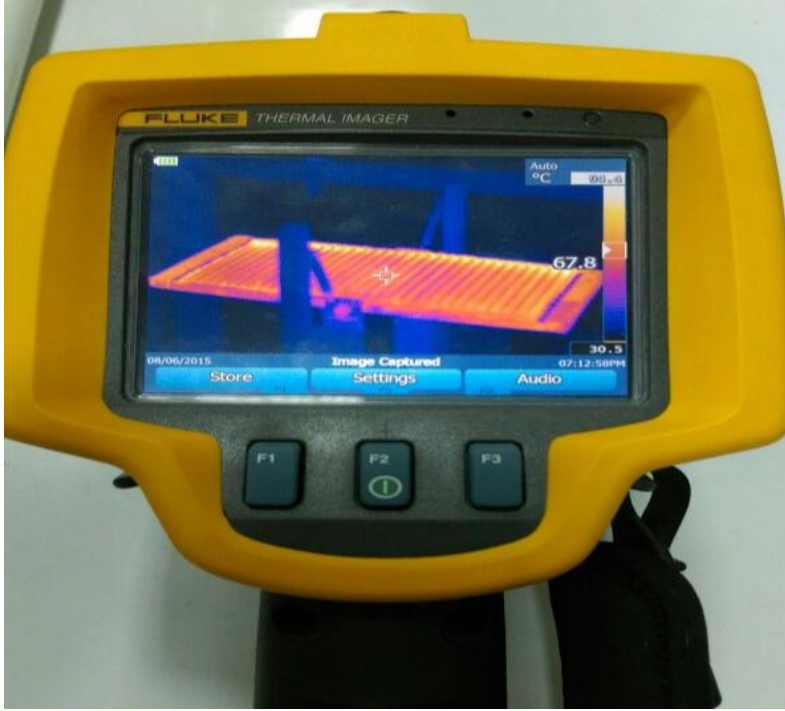

Fig 3: Photography of the Thermal Camera.

\subsection{Uncertainty Analysis}

Random Error refers to the deviation or the spread in the values of a variable (physical quantity) from one measurement of the variable to the next, due to the random fluctuations in the measured value. The problem's solution is to repeat the measurement several times; this uncertainty analysis is based on the method is suggested by the reference [11].

The maximum measurement uncertainties were: the heat flux $\pm 6.73 \%$, while $\pm 7.14 \%$ for the heat transfer coefficient, $\pm 7.26 \%$ of the Nesselt number, $\pm 3.96 \%$ for Rayleigh number and $\pm 8.98 \%$ for the vibrational Reynolds number.

\section{RESULTS AND DISCUSIONS}

The Fig 5: explains the effect of the Rayleigh number (Ra) on the mean Nesselt number $\left(\mathrm{Nu}_{\text {mean }}\right)$ of all applied heat fluxes and for the horizontal, vertical and facing downward positions where it clarifies the increasing of the Rayleigh number leads to increase the mean Nesselt number in all applied heat fluxes and for the three positions above. As well as it can be noticed high proportional increasing on the value of the mean Nesselt number when the Rayleigh number range from $1.5 \times 10^{8}$ to $2.0 \times 10^{8}$ because of the significant increasing in the heat transfer coefficient when the heat flux change from [250 to $\left.500 \mathrm{~W} / \mathrm{m}^{2}\right]$.

Fig 6: illustrates the influence of vibration amplitude on the mean vibrational Nesselt number, where the vibration amplitude increases, then the mean vibrational Nesselt number increased accordingly for all applied heat fluxes and for the horizontal position, because of the increasing of the vibrational amplitude leads to increase the vibration density (intensity), which cause a certain increase of the $N u v_{\text {mean }}$, which in accordance with the reference [12]. So the maximum value of the mean vibrational Nesselt number is achieved when the vibration amplitude is equal to (5 $\mathrm{mm}$ peak to peak) for all applied heat fluxes and all applied frequencies and for the three positions; therefore all the following calculations and results are based on constant vibration amplitude is considered to $(5 \mathrm{~mm})$.

Fig 7: illustrates the vibrational mean Nesselt number with the vibrational Reynolds number of the horizontal, vertical and facing downward position for all applied heat flux. It can be noticed that the vibrational mean Nesselt number increases when the vibrational Reynolds number is increased for the 
three positions as well as the vibrational mean Nesselt number in the horizontal position is higher than that of vertical position which is in turn higher than that of facing downward position

Fig 8,9 and 10: demonstrate the mean Nesselt number in the both cases, in case of vibration's absence and in case of vibration's existence according to the method of reference [2], for the horizontal, vertical and facing downward positions. It can be noticed that the vibration applying make augmentation on the mean Nesselt number and the better enhancement is in the horizontal position with percentage $(9.5 \%)$ while the percentage of enhancement of the vertical position is $(7.5 \%)$ whereas the enhancement percentage of the facing downward position is $(5.8 \%)$. applied frequency ranges (the $N u v_{\text {mean }}$ increase when the applied frequency is increased); however the value of the $N u v_{\text {mean }}$ of Serhan study is higher than that of the present study, this difference may be attributed to there is 16 sets of fin-arrays work to augment the amount of convective heat as well as the higher applied vibration amplitude.

\section{CONCLUSIONS}

- The vibrational mean Nesselt number increases, when the vibration amplitude is increased in all investigated cases.

- The vibrational Nesselt number increases, when the vibrational Reynolds number is generally increased, but the amount of this increasing depending on the position of the sinusoidal surface.

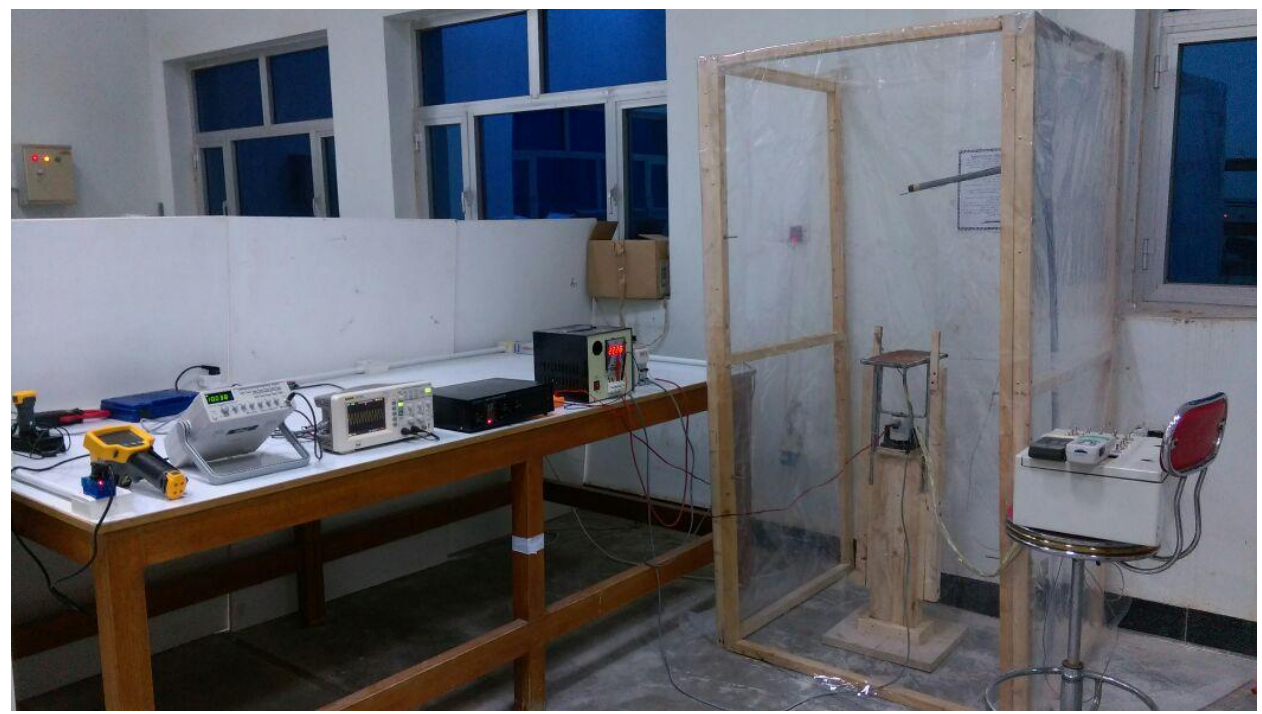

Fig 4: photograph of installation of the whole system.

Fig 11: represents a comparison between this study and Saleh study reference [1] for the mean Nusselt number $\left(N u v_{\text {mean }}\right)$, where Saleh study deals with the effect of vibrating Vgrooved impingement plate on heat transfer by forced convection from the heated air jet. The comparison is achieved of the following conditions for Saleh study, where the Reynolds number $(\mathrm{Re}=1700)$, vibration amplitude $\left(a_{v}\right)=10 \mathrm{~mm}$ and frequency range (from 10 to $25 \mathrm{~Hz}$ ). It clarifies that the mean Nusselt number is high proportional increased when the Nesselt number increased until 15 in both studies while it witnesses a significant difference beyond 15 $\mathrm{Hz}$ where the $N u v_{\text {mean }}$ of present study shows very little increasing in contrast of Salah study, which keeps on the same behavior (high proportional increase) and these may be attributed to the high value of vibration amplitude of Salah study, which is being more effective in high frequency range as well as Saleh study is applied for forced convection conditions which is originally turbulent and applying high frequency cause a significant increase in the flow turbulence leads to increase the rejected heat transfer.

Serhan [7] presents an experimental study to the free convection from longitudinally finned plate under conditions of constant heat flux same with the present study as well as applied frequency ranges including of the ranges of the present study except the amplitude range (from 1.63 to 7.16 $\mathrm{mm})$ which higher than this study. Fig 12: explains the vibrational mean Nesselt number $\left(N u v_{\text {mean }}\right)$ of both studies for all applied heat flux and each applied frequency. It can be observed that the both studies have the same behavior in all
- In the horizontal and vertical positions, the lower ranges $(2000,4000,6000)$ of the vibrational Reynolds number have a powerful enhancement on the vibrational mean Nesselt number; while the higher ranges (8000 and 10000) have an insignificant influence on the $N u v_{\text {mean }}$.

- In the facing downward position, the higher ranges (6000 and 8000$)$ of the vibrational Reynolds number $\left(R e_{v}\right)$ have a powerful influence on the $N u v_{\text {mean }}$; while the lower range of $R e_{v}$ (2000 and 4000) have a little influence on the value of $N u v_{\text {mean }}$.

- The vibrational Nesselt number is governed by the Rayleigh number, vibrational Reynolds number and the position of the sinusoidal surface.

\section{RECOMMANDATIONS}

- Study the influence of vibration on the forced convection heat transfer from pipes, cylinder and sphere.

- Study the effect of the acoustic vibration on the heat transfer and compared with a vibrated plate at the same conditions. 


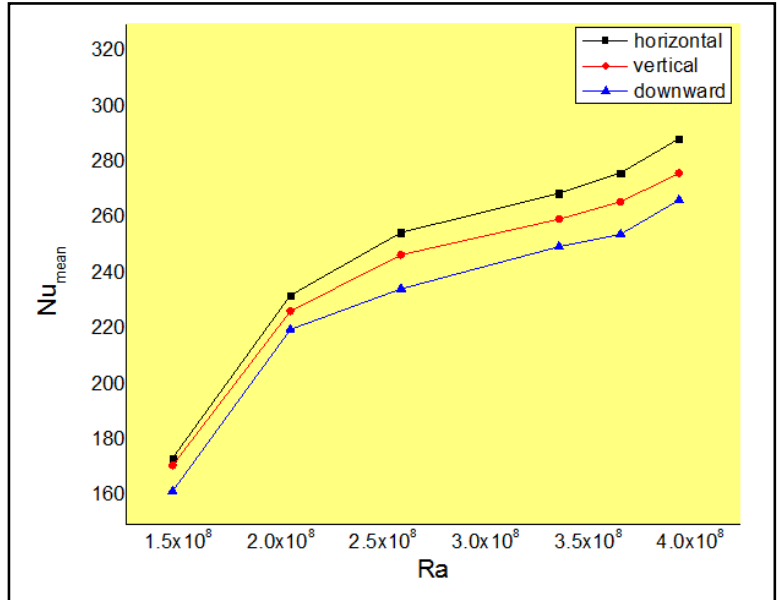

Fig 5: explains the effect of the Rayleigh number (Ra) on the mean Nesselt number $\left(\mathrm{Nu}_{\text {mean }}\right)$.

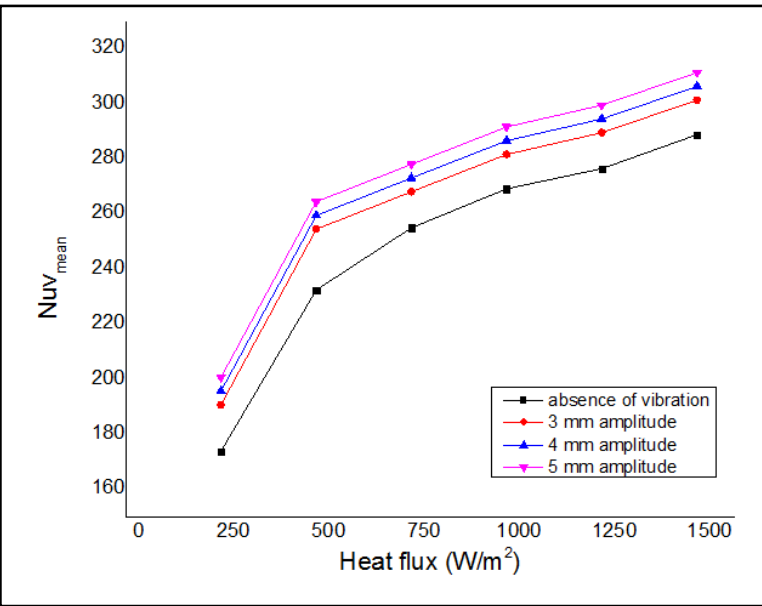

Fig 6: effect of vibration amplitude on the $N u v_{\text {mean }}$

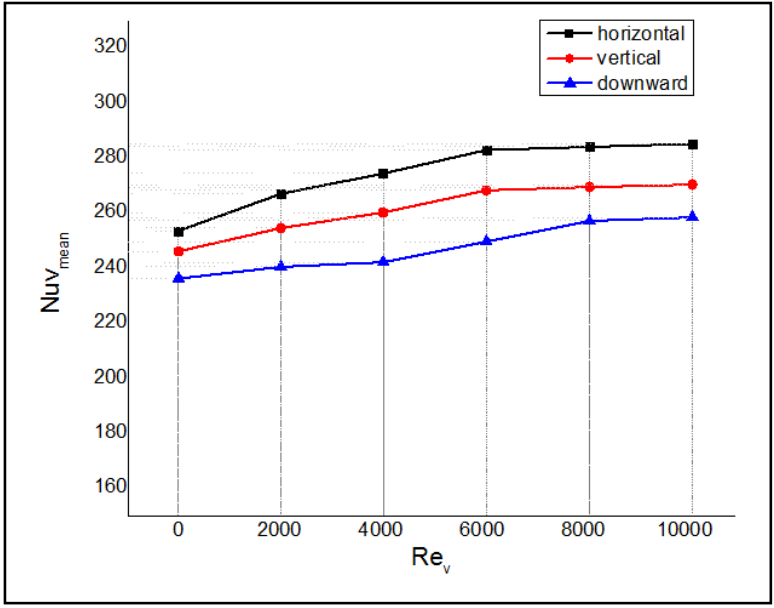

Fig 7: the effect of the vibrational Reynolds number on the vibrational mean Nesselt number and of the horizontal, vertical and facing downward position for all applied heat flux.

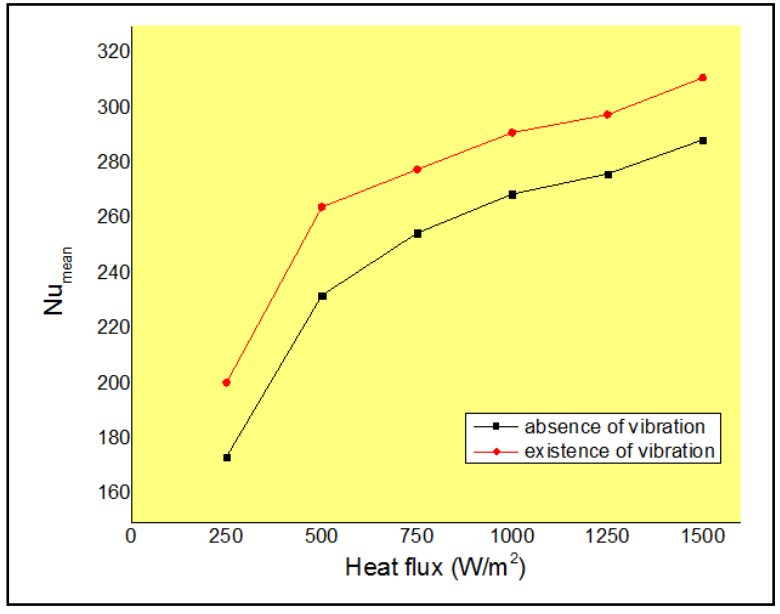

Fig 8: Comparison of the mean Nesselt number value with and without vibration for the horizontal position.

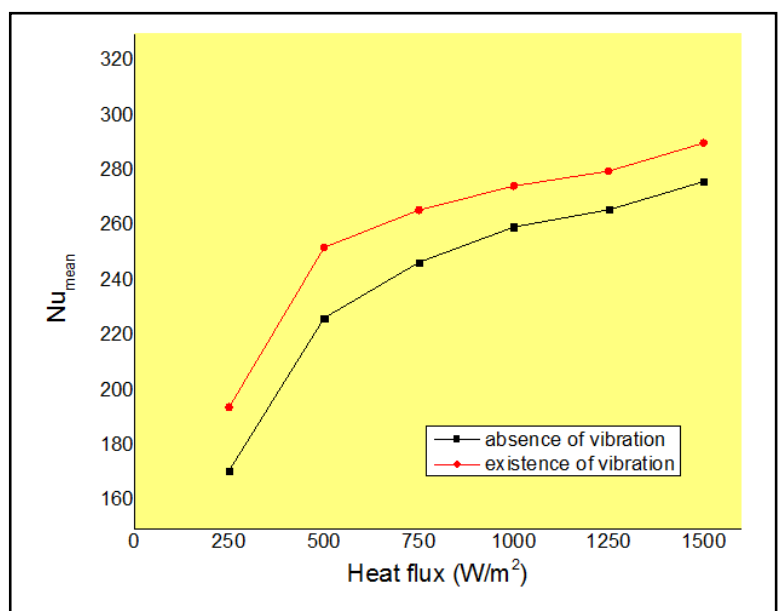

Fig 9: Comparison of the mean Nesselt number value with and without vibration for the vertical position.

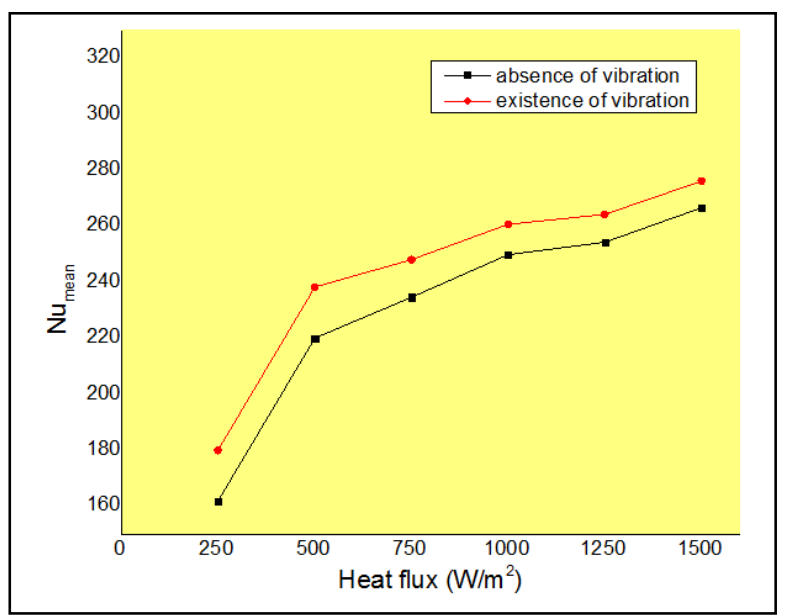

Fig 10: Comparison of the mean Nesselt number with and without vibration for the downward position. 


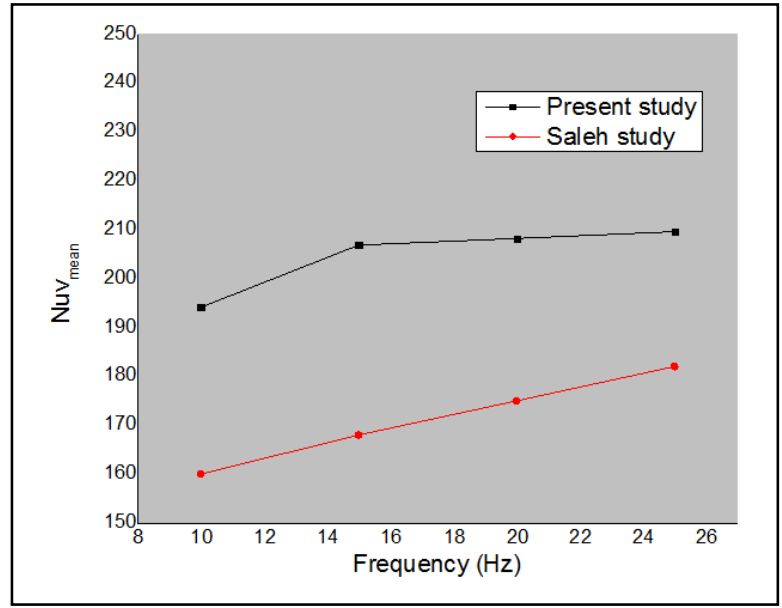

Fig 11: Comparison with Saleh's study ref [1].

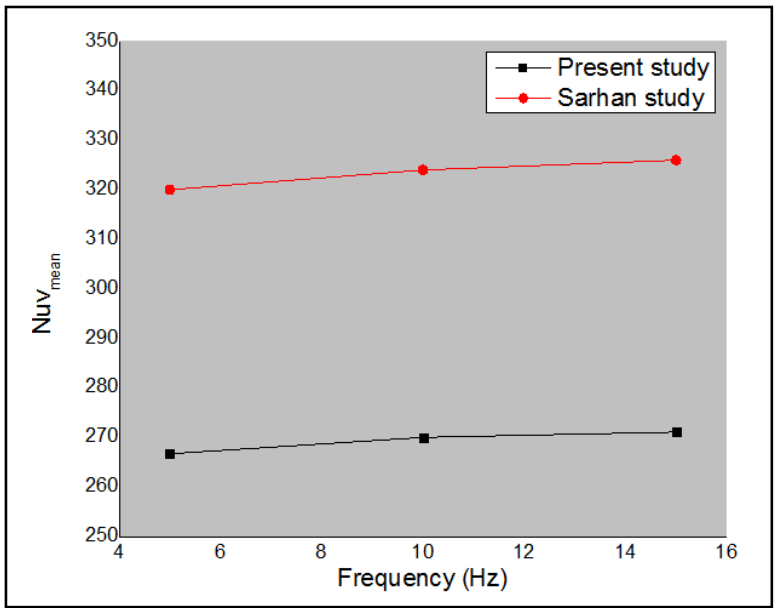

Fig 12: Comparison with Sarhan's study ref [7].

\section{ACKNOWLEDGMENTS}

I wish to express deepest gratitude to my supervisor, Professor Dr. Zena K. Khadim, the vice dean of Engineering college at Wasit University, for her support, guidance, motivation and wonderful personality. Her enthusiasm and expertise in this scope have granted me a wealth of knowledge and experiences that are invaluable. Great thank to Eng. Ma Cuxiang of the ALWAHA petroleum company for his help to provide me the necessary devices to implement the experiments.

\section{REFERENCES}

[1] M. A. Saleh, 2006 "Enhancement of Convective Heat Transfer on A Flat Plate by Artificial Roughness and Vibration", International Conference on Heat and Mass
Transfer, Miami, Florida, USA, January 18-20, 2006 (pp69-77).

[2] K. Krishna Prasad and V. Ramanathan, "heat transfer by free convection from a longitudinally vibrating plate ", Ini. J. Heat Mass Transfer, vol. 15, pp. 1213-1223. Pergamon Press, 1972. Printed in Great Britain.

[3] Kenji Takahashi and Kazuo Endoh. (1990), “A new correlation method for the effect of vibration on forced convection heat transfer" Journal of chemical engineering of Japan. Vol.23, No.1, pp.45-50.

[4] M. Ashjaee - M. Amiri - J. Rostami, "A correlation for free convection heat transfer from vertical wavy surfaces", Published online, January 2007.

[5] M. N. Hasan*, S. Saha and S. C. Saha, 2011, "Effects of corrugation frequency and aspect ratio on natural convection within an enclosure having sinusoidal corrugation over a heated top surface" International Communications in Heat and Mass Transfer, 39(3), pp. 368-377.

[6] S.H.Bhavnani, Auburn, Alabama and A.E. Bergles, "Natural convection heat transfer from sinusoidal wavy surface", Springer-Verlag Vol.26, PP. (341-349),(1991).

[7] Abdalhamid Rafea Sarhan, "Vertical Forced Vibration Effect on Natural Convective Performance Longitudinal Fin Heat Sinks", Tikrit Journal of Engineering Sciences/Vol.20/No.2/March 2013, (60-69).

[8] Dr. Zena K. Kadhim and Fadi R. Shamon, "Experimental study of the effect of vertical vibrations on forced convection heat transfer coefficient from circumferentially finned cylinder", journal of engineering and technology,number17, volume 14, 2010.

[9] Behrouz Takabil and Saeed Salehi, " Augmentation of the Heat Transfer Performance of a Sinusoidal Corrugated Enclosure by Employing Hybrid Nanofluid", Hindawi Publishing Corporation, Advances in Mechanical Engineering, Volume 2014, Article ID 147059, 16 pages.

[10] Mesut Tekkalmaz, "Natural convection heat transfer and air flow in rectangular enclosures with a wavy wall", Is1 Bilimi ve Tekniği Dergisi, 33,1, 21-31, 2013. J. of Thermal Science and Technology (C2013 TIBTD Printed in Turkey ISSN 1300-3615.

[11] Measurement Uncertainty, International Atomic Energ Agency, IAEA-TECDOC-1585, May, 2008.

[12] Assist. Prof. Dr. Majid. H. M. Al-Shorafa'a, "A study of influence of vertical vibration on heat transfer coefficient from horizontal cylinders", Journal of Engineering, Volume14 March 2008. 